\title{
Desdobramentos recentes da educação inclusiva no Brasil: discursos e práticas de letramento
}

\section{Recent developments in inclusive education in Brazil: discourses and literacy practices}

Denise Tamaê Borges Sato*

Universidade de Brasília (UnB)

Brasília - Distrito Federal/Brasil

Izabel Magalhães**

Universidade de Brasília (UnB)

Brasília - Distrito Federal/Brasil

Universidade Federal do Ceará (UFC)

Fortaleza - Ceará/Brasil

José Ribamar Lopes Batista Júnior***

Universidade Federal do Piauí (UFPI)

Teresina - Piauí/Brasil

Universidade de Brasília (UnB)

Brasília - Distrito Federal/Brasil

RESUMO: A oferta da educação para pessoas com deficiência sofreu modificações significativas no contexto social brasileiro. Desse contexto de transformaçôes, surgiram os projetos integrados "Discursos, Identidades e Práticas de Letramento no Ensino Especial" e "Múltiplos Letramentos, Identidades e Interdisciplinaridades no Atendimento Educacional à Pessoa Deficiente", em que se aliou a pesquisa etnográfica à Análise de Discurso Crítica e aos Novos Estudos do Letramento para examinar discursos e identidades profissionais que emergem desse contexto. ${ }^{1}$ Ao longo de cinco anos de investigação, os resultados sugerem que as identidades de professores e professoras são levadas à transformação como parte de um processo criado pela formação inadequada nos níveis iniciais para atuação no Ensino Especial, bem como pela tentativa de suprir lacunas por meio de seus letramentos diários e pedagógicos. PALAVRAS-CHAVE: discurso, letramento, educação inclusiva.

* denisetamae@gmail.com

**mizabel@uol.com.br

*** ribasninja@gmail.com

${ }^{1}$ A coordenação de ambos os projetos é de Izabel Magalhães, pesquisadora do CNPq. 
ABSTRACT: Education provision for people with disabilities has undergone considerable changes in the Brazilian social context. As part of these changes, two research projects have been developed: "Discourses, Identities and Literacy Practices in Special Education", and "Multiple Literacies, Identities and Interdisciplinarities in the Specialized Educational Care for Learners with Disabilities". These projects propose to relate ethnographic research, Critical Discourse Analysis and the New Literacy Studies in order to examine professional discourses and identities emerging from this context. Over five years of research, the results suggest that teachers' identities have changed as part of a process stemming from inadequate education in the initial stages to teach learners with disabilities and the teachers' attempt to overcome this gap through their daily and pedagogic literacies.

KEYWORDS: discourse, literacy, inclusive education.

\section{Introdução}

O presente estudo é resultado de pesquisas realizadas em quatro estados brasileiros - Distrito Federal, Goiás, Ceará e Piauí -, nos últimos cinco anos. As pesquisas investigam os discursos e os letramentos no contexto da Educação Especial, em face das mudanças na política educacional brasileira, que promoveram a inclusão de pessoas com deficiência nas escolas regulares. Institucionalmente, as mudanças se deram em consonância com as orientações estabelecidas na Conferência Educação para Todos (1990) e na Declaração de Salamanca (1994), que preconizavam, entre outras questões, a ampliação da Educação Especial nos países em desenvolvimento. ${ }^{2}$ Contudo, tal processo repercutiu no modelo educacional da escola regular comum, desarticulou a rede de atendimento ofertado até então por associaçôes e organizações não governamentais e desencadeou diferentes práticas identitárias em professores e professoras, dentro do modelo inclusivo.

O objetivo deste artigo é analisar discursos e letramentos no contexto da educação inclusiva, examinando seus significados como formas de ação, representação e identificação. Adotamos o arcabouço teórico da Análise de Discurso Crítica e da Teoria Social do Letramento (STREET, 1984, 2001; BARTON, 2007; PRINSLOO; BREIER, 1996; BARTON, HAMILTON, 1998; BARTON, HAMILTON, IVANIC, 2000; RIOS, 2009). Os conceitos adotados são os que se alinham à proposta de Fairclough (2003): o discurso, um dos elementos da prática social, é entendido como forma de ação, representação e identificação. Discursos e identidades docentes estão

${ }^{2}<$ http://portal.mec.gov.br/seesp>. Acesso em: 25 mar. 2012. 
situados em práticas de letramento (STREET, 1984, 1995; MAGALHÃES, 2008). Adotamos, igualmente, como metodologia a pesquisa etnográficodiscursiva, combinada com o estudo de narrativas (MAGALHÃES, 2006).

Ao relacionarmos a pesquisa etnográfica e a Análise de Discurso Crítica para investigar práticas de letramento e identidades docentes, pretendemos contribuir para a compreensão das implicaçôes representadas pela rearticulação dos elementos da prática social de inclusão (BATISTA JR., 2008; SATO, 2008). Este artigo está dividido em quatro seçōes. As duas primeiras serão dedicadas a uma discussão teórica sobre a Análise de Discurso Crítica e os Novos Estudos do Letramento; a terceira apresentará a pesquisa etnográfica e o contexto da pesquisa. A análise dos dados obtidos no Distrito Federal, em Goiás, no Ceará e no Piauí, na quarta seção, é uma tentativa de elucidação da proposta de inclusão das pessoas com deficiência na prática escolar. Em seguida, teceremos algumas considerações finais.

\section{Análise de Discurso Crítica}

A Análise de Discurso Crítica (ADC) propóe examinar os modos pelos quais o abuso de poder, a dominação e as desigualdades são sustentados ou combatidos por meio de textos orais, escritos, visuais ou multimodais, em contextos específicos, sociais e políticos (VAN DIJK, 1999). Ainda que não percebamos, materialmente, em que momento o poder é iniciado ou de que maneira ele é promulgado, sabemos que ele se estabelece por meio da força de instituiçôes como o Estado e a Igreja, e de formas de manipulação ideológica (MAGALHÃES, 2008).

A contextualização do discurso é, certamente, um desafio a estudiosos e analistas para que se consiga alcançar a prática discursiva. Os textos não surgem de forma aleatória. Sua produção, os discursos a que recorrem e a recepção atendem a demandas geradas pelas instituiçōes centralizadoras, num sistema de poder policêntrico. Esse poder descentralizado compartilha alguns discursos comuns às práticas sociais, formando uma rede, por meio da qual se reforçam na medida em que se naturalizam (CHOULIARAKI; FAIRCLOUGH, 1999).

O significado depende do discurso e dos demais elementos da prática. O discurso predispõe os atores sociais a determinadas açōes, direcionando-os a assumir comportamentos consoantes com a prática social a que pertençam. Os sujeitos que incorporam as ideias e significados de uma prática tomam esse espaço como sua realidade (SATO, 2008). Nesse sentido, o conjunto de conhecimentos representa formas de interagir com o espaço e, ao mesmo 
tempo, faz com que os atores sintam-se parte desse ambiente, e é o que torna significativa cada vivência.

O discurso assume, nas práticas sociais, seus três significados principais, conforme Fairclough (2003): acional, representacional e identificacional. Os modos de ver e compreender determinados fenômenos sociais são, dessa forma, construções sociais complexas, que envolvem também outros elementos da prática, inclusive os elementos não discursivos (FOUCAULT, 1987).

Para compreender a prática social, a Análise de Discurso deve incluir em seu objeto de pesquisa tanto a linguagem como a ação ou os significados sociais que a estabelecem (BLOMMAERT, 2005; FAIRCLOUGH, 2010). Se o estudo da estrutura do código linguístico não alcançava o social, os teóricos da linguagem foram buscar em outros campos as ferramentas de estudo, como a Crítica Literária, a Sociologia, a Filosofia, a Antropologia, a Semiótica, entre outros. Os desenvolvimentos que se iniciaram com a Linguística SistêmicoFuncional e a Linguística Crítica deram ao estudo do discurso como prática social um perfil complexo (MAGALHÃES, 2004). Para analistas críticos do discurso, uma questão é pacífica: a visão de que o discurso seja uma prática social e de que os estudos linguísticos baseados no discurso poderiam constituir uma ferramenta eficiente para estudos atuais. Fairclough (2003) define o discurso como campo fértil para a análise dos mecanismos da globalização e dos fenômenos sociais da modernidade posterior. Assim, o "estudo do discurso é uma forma de debater e criticar a exclusão praticada e representada nas práticas socioculturais" (MAGALHÂES, 2011, p. 218).

O discurso, assim, conecta-se a um conjunto de articulações, pelas quais a linguagem cruza fronteiras, estabelecendo configurações com diferentes discursos que, por sua vez, influenciam ou constrangem a atividade de atores sociais nos eventos. Os discursos de uma prática em sua totalidade constituem as "ordens do discurso" (FOUCAULT, 1980; FAIRCLOUGH, 2003). Ordens do discurso são formaçôes sociais de linguagem e elementos semióticos relativamente duráveis, os quais, por sua vez, são elementos estruturais hierarquizados de uma rede de práticas sociais (FAIRCLOUGH, 2010). Por fim, as ordens do discurso são a totalidade de práticas discursivas dentro de uma instituição ou sociedade, e o relacionamento entre elas é, para Fairclough (2001), decisivo, porque define o cerne de qualquer prática social.

Contudo, faltam à ADC mecanismos de investigação in locum, os quais Fairclough (2003) reconhece; como medida corretiva, o teórico britânico recomenda a articulação com métodos etnográficos, sem ater-se a maiores detalhamentos sobre como tais estudos se processariam. 
Esta apresentação sucinta da ADC foi necessária para uma reflexão sobre aspectos supratextuais que concorrem na formação da ordem do discurso: a organização dinâmica e hierárquica das práticas discursivas (FAIRCLOUGH, 2010). Com isso, defendemos a relação entre a ADC e a Teoria Social do Letramento (TSL), cujo foco está nos usos sociais da leitura e da escrita, que passaremos a comentar na próxima seção.

\section{Novos Estudos do Letramento e ADC}

Gee (2000) discorre sobre o letramento como um tipo de prática construída a partir de uma linguagem distinta, formas linguísticas elaboradas para a mediação em atividades situadas, também construídas socialmente. Para o autor, os textos escritos veiculam discursos que influenciam e controlam a linguagem que determinados grupos de pessoas utilizam para interagir, estabelecer valores, fazer acreditar e até mesmo falar (GEE, 2000, p. 413). Esses textos formam um conjunto de semioses, que incluem todas as formas de construção de significados (FAIRCLOUGH, 2001, p. 122), e que constituem formas de conhecimento, de ser, de estar no mundo. Tais conhecimentos influem no significado pessoal, na identidade, transparecendo em linguagem corporal, imagens visuais que refletem os modos de ser, enfim, a própria identidade.

Assim, as lutas pelas identidades são lutas pelo poder e pela posse de representações de prestígio. Nesse sentido, o acesso aos letramentos pode ser visto como uma forma de aquisição dessas representações e dos modos de agir com a língua. Por meio do acesso aos letramentos de prestígio, novos atores podem ser situados em práticas constituídas, bem como, por meio da exposição de atributos relacionados aos letramentos de prestígio pelos atores sociais, novas propostas de mudança podem ocorrer, via processos de identificação.

Esses processos podem variar, pois os gêneros discursivos diferem em graus de poder e ideologia (STREET, 1998). Textos com maior prestígio interferem na prática ou no conjunto de práticas de um número maior de pessoas do que outros com menor prestígio. Textos governamentais regem atividades. Textos publicitários influenciam comportamentos. Textos cotidianos operacionalizam dinâmicas. Práticas domésticas de letramento determinam o quanto esses outros textos adentram o lar e de que forma uma família está situada em diferentes contextos sociais. Os textos lidos em um ambiente familiar dizem sobre a posição social de seus leitores. Quem os produz demonstra a posição social que ocupa. De igual sorte, a leitura e a escrita vão ser carregadas desses sentidos, e têm uma forma "situada", ou seja, uma forma de ler e de escrever correspondente ao mundo social em que o discurso foi produzido. 
Gee (1999) defende, ainda, que os estudos do letramento devem centrarse no trabalho de percepção de como as pessoas conseguem reconstruir, manter, negociar, resistir a identidades ou situaçóes impostas. Relações assimétricas de poder tendem a constranger as pessoas a falar, pensar, agir e posicionar-se de uma forma particular, a aceitar certas maneiras de ver a si mesmas e encarar o mundo; contudo, os diferentes letramentos e, dentre eles, os letramentos críticos, são poderosas ferramentas de atuação que atores locais podem utilizar para romper barreiras impostas pelas estruturas sociais e alçarse em busca de novas configuraçōes sociais (STREET, 1995).

Um dos aspectos inerentes a ambas as teorias, ADC e TSL, é o foco nas identidades como forma explanatória das operacionalidades do poder e da ideologia. Na articulação proposta, temos, em Adult literacy, numeracy and language, de Lyn Tett, Mary Hamilton, e Yvonne Hillier (2006), a relação entre letramento e inclusão como fatores políticos. A ADC relaciona o uso da linguagem a significados identificacionais, sendo, nesse caso, o uso da linguagem escrita (letramento) uma forma de interação na qual as pessoas são envolvidas (FAIRCLOUGH, 2003).

No alargamento da compreensão sobre eventos de letramento (HEATH, 1983), compreendemos eventos como espaços em que as pessoas criam, coletivamente, significados na interação com os outros, por meio de suas histórias individuais e coletivas, em situações pertinentes (BLOOME $e t$ al. 2005, p. 6). Esse alargamento permite a articulação entre TSL e ADC, uma vez que, ao produzir significados nos eventos de letramento, as identidades se constroem, recriam seus espaços e possibilitam a manutenção ou transformação das práticas. Cabe, então, a analistas do discurso e do letramento a tarefa de problematizar as articulaçóes que sustentam práticas, ou, ainda, buscar a compreensão de mecanismos de poder nelas engendrados.

\section{Etnografia e o contexto da pesquisa}

Este estudo consiste na combinação da pesquisa etnográfica com a Análise de Discurso Textualmente Orientada (ADTO), um método de análise associado à ADC. A etnografia compreende "a arte e a ciência de descrever um grupo humano - suas instituições, seus comportamentos interpessoais, suas produçôes materiais e suas crenças" (ANGROSINO, 2009, p. 30). Em outras palavras, como sugerem Hammersley e Atkinson (2007): 
[...] a etnografia envolve a participação de pesquisadores, aberta ou veladamente, na vida diária das pessoas por um período prolongado de tempo, observando o que acontece, ouvindo o que é dito e/ou fazendo perguntas mediante entrevistas informais e formais; também recolhem documentos e artefatos - de fato, reunindo todos os dados disponíveis para jogar luz sobre as questôes que são o foco emergente da pesquisa. De um modo geral, etnógrafos e etnógrafas recorrem a uma variedade de fontes de dados, embora possam basear-se, com frequência, principalmente em uma fonte específica (HAMMERSLEY; ATKINSON, 2007, p. 3, tradução nossa).

Embora haja discordância, por exemplo, em Heath e Street (2008), a pesquisa etnográfica é entendida, aqui, como uma abordagem qualitativa, que é "indicada quando se pretende focar representações de mundo, relações sociais, identidades, opiniōes, atitudes, crenças ligadas a um meio social" (RESENDE, 2009 , p. 57). Essa abordagem tem o ambiente natural como sua fonte direta de dados e o pesquisador ou a pesquisadora como seu principal instrumento, isto é, supõe o contato direto e prolongado dessa pessoa com o ambiente e a situação que está sendo investigada (FLICK, 2009a, 2009b).

Os dados deste estudo foram gerados e coletados por meio de observações (na primeira etapa da pesquisa) e de entrevistas etnográficas, narrativas e registros de diários (na segunda etapa) realizados em oito escolas regulares públicas inclusivas de quatro Estados do Brasil: Ceará (Fortaleza), Distrito Federal (Brasília e Taguatinga), Goiás (Goiânia e Planaltina de Goiás) e Piauí (Teresina), no período de outubro de 2007 a dezembro de 2011. Os participantes são trinta profissionais de diversas áreas (Educação, Saúde, Psicologia, Assistência Social). Porém, neste artigo, vamos focar os profissionais da educação.

\section{Práticas de letramento inclusivo ${ }^{3}$ e discursos da educação especial}

Nesta seção, vamos analisar práticas de letramento inclusivo, discursos, e como ambos operam na construção das identidades docentes. A análise se detém

\footnotetext{
${ }^{3}$ Práticas de letramento "referem-se tanto a comportamentos como a conceituaçóes sociais e culturais que dão significado à leitura e/ou à escrita" (STREET, 1995, p. 2, tradução nossa). O conceito de prática de letramento é um desenvolvimento de evento de letramento, que significa qualquer ocasião em que a linguagem escrita faz parte do processo interacional e interpretativo dos participantes (HEATH, 1983). Portanto, nos eventos encontram-se textos falados, escritos e multimodais.
} 
em entrevistas e narrativas, bem como em textos indicados por professores e professoras, e em textos institucionais relacionados às atividades escolares.

\section{O cotidiano escolar e os letramentos}

Os letramentos diários são usos da leitura e da escrita que integram a rotina das pessoas em diferentes contextos. No ambiente das escolas pesquisadas, eles estão presentes nos murais, nos corredores, nas salas de aula, na sala de professores e professoras e em solenidades, e em cada ambiente o uso da leitura e da escrita assume configurações específicas e atende a objetivos específicos, conforme o QUADRO 1, a seguir:

\section{QUADRO 1}

O cotidiano escolar e os letramentos

\begin{tabular}{|c|c|}
\hline Letramentos & Descrição \\
\hline Acadêmico & $\begin{array}{l}\text { Cartazes no mural com informações de cursos para atualização, } \\
\text { aperfeiçoamento. }\end{array}$ \\
\hline Institucional & $\begin{array}{l}\text { Contato direto entre administração escolar, professores/as, alunos/as, } \\
\text { visitantes e a entrega de circulares, comunicados vindo da Secretaria } \\
\text { de Educação. }\end{array}$ \\
\hline Informal & $\begin{array}{l}\text { Quadro de aniversário dos/as professores/as, frases, mensagens de } \\
\text { reflexão e incentivo. }\end{array}$ \\
\hline Pedagógico & $\begin{array}{l}\text { Quando os/as professores/as preparam suas aulas, discutem as } \\
\text { atividades e os conteúdos a serem ministrados, bem como a leitura e a } \\
\text { produção escrita, na maioria das vezes uma atividade individual. }\end{array}$ \\
\hline Comercial & $\begin{array}{l}\text { No momento em que uma professora recolhe as contribuições para o } \\
\text { lanche dos docentes, a compra e a venda de bijuterias, roupas. }\end{array}$ \\
\hline Digital & $\begin{array}{l}\text { Quando o/a professor/a produz uma atividade, entretanto, está presente } \\
\text { de maneira tímida, pois há } 1 \text { (um) único computador, porém é pouco } \\
\text { utilizado, principalmente, pela falta de acesso à internet. }\end{array}$ \\
\hline Religioso & Mural com a figura de Jesus e mensagem bíblica. \\
\hline Burocrático & Formulários, diários, canhotos de notas. \\
\hline
\end{tabular}

Os usos diários, principalmente aqueles a que temos acesso em nossa infância, são como pontes de significado para os demais letramentos, ou como janelas pelas quais percebemos o que há ao nosso redor. Por meio dos letramentos, podemos assimilar crenças, princípios e valores relacionados à atividade e ao papel em que nos situamos. 
Por meio dos letramentos diários, percebemos que o discurso da escola tradicional é forte nas práticas educacionais das escolas, o que nos leva a pressupor que as identidades docentes, inclusive de gênero, serão igualmente atravessadas pela concepção de ensino presente no discurso tradicional.

\section{Práticas de letramento inclusivo: discursos e identidades}

Consideramos como práticas de letramento inclusivo as práticas nas quais os textos exercem influência direta ou indireta no processo de tornar a pessoa com necessidades educacionais especiais incluída na vida social (SATO, 2008; BATISTA JR, 2008). Dentre as práticas escolares, encontraremos as de letramento inclusivo burocrático-administrativo na ação da professora itinerante e na prática de letramento inclusivo pedagógico, promovido pela atividade docente, no processo de inclusão de alunas e alunos com surdez ou Síndrome de Down, bem como no Atendimento Educacional Especializado à pessoa com deficiência.

\section{A inclusão de alunos e alunas surdos}

Analisaremos, aqui, os eventos de letramento pelos quais buscamos enxergar as práticas de letramento no processo de inclusão de alunos e alunas surdos, bem como os gêneros discursivos relacionados a essas práticas e, consequentemente, o processo de construção das identidades docentes, em duas escolas do Distrito Federal.

a) Gêneros discursivos e identidades nas práticas de letramento inclusivo

No letramento inclusivo, as práticas com os textos auxiliam na inclusão da pessoa com necessidades educativas especiais. Assim, percebemos a reconfiguração, a adaptação dos gêneros discursivos em sala de aula com relação à estrutura funcional, à estrutura composicional e às escolhas lexicais para facilitar as práticas de sala de aula (BAKHTIN, 1997). Dessa forma, percebe-se uma mudança tímida das práticas de letramento. No QUADRO 2 , a seguir, apresentamos os gêneros discursivos comentados nas entrevistas com docentes e nos diversos eventos de letramento observados. 


\section{QUADRO 2}

Gêneros discursivos nos eventos de letramento

\begin{tabular}{|l|l|l|}
\hline Participante & Evento de letramento & Gêneros discursivos \\
\hline Ana Kalyne & Aula de Matemática & $\begin{array}{l}\text { (Laboratório de informática) } \\
\text { Cartazes }\end{array}$ \\
\hline Ana Kalyne & Aula de Ciências (teoria) & Cartazes \\
\hline Mara & Aula de História (teoria) & Desenhos/Questionário/Exercício \\
\hline Rosa & Aula de Geografia (teoria e prática) & $\begin{array}{l}\text { Desenhos/Maquete/Mapas } \\
\text { Relato/Narrativas }\end{array}$ \\
\hline Teresa & Aula de Ciências (teoria) & Resumo/Questionário/Exercício \\
\hline Teresa & Aula de Ciências (prática) & Relatório/Desenho \\
\hline Cleia & $\begin{array}{l}\text { Aula de Português Brasileiro } \\
\text { como Segunda Língua (PBSL) }\end{array}$ & Crônicas \\
\hline Goreth & Aula de PBSL & Reportagem/Notícias \\
\hline Batista & Aula de Ciências & Resumo/Exercício \\
\hline
\end{tabular}

O desenho é citado pela maioria das professoras, principalmente nas falas daquelas que trabalham com Ciências, Geografia e História. Esse gênero discursivo está presente sempre nas aulas e atividades, não simplesmente com a intenção de preencher espaço da aula ou para passar o tempo, mas para a avaliação, na maneira de as professoras observarem até que ponto determinado conteúdo foi compreendido pelos alunos.

Os gêneros discursivos são formas mais ou menos estáveis de composição textual, por meio das quais atividades concretas do mundo real ganham regularidade nas práticas sociais, certa rotina, um modo de fazer as coisas. Como exemplo, podemos citar a receita médica, gênero que pertence à prática da saúde. Dentro da prática da saúde, o gênero receita faz parte de um rito: a consulta, o diálogo e depois a emissão da receita por parte do médico ou terapeuta. Esse gênero está circunscrito a essa prática.

Igualmente, alguns gêneros textuais fazem parte apenas do contexto da escola, como é o caso da redação comum ou do diário de classe. Outros extrapolam a escola, como é o caso da prova de conhecimentos, que também é utilizada em concursos. Dentro do letramento, o uso e o domínio desses gêneros dizem do nível de assimilação que determinados participantes apresentam em relação à prática da qual o gênero emerge. Quando um tipo de composição se torna habitual e seu domínio é pleno, como as mensagens de celular utilizadas por crianças e jovens, podemos dizer que essa familiarização 
com o gênero sugere a identificação que a pessoa tem com o papel desempenhado na prática, no caso, interlocutor ou interlocutora via celular/SMS.

$\mathrm{Na}$ educação regular inclusiva, um aspecto observado é a falta de identificação com os gêneros discursivos por parte de professores e professoras (de qualquer área, inclusive Língua Portuguesa), visto que eles ou elas não apresentam uma escolha lexical própria dos gêneros discursivos mais frequentes, apesar de os utilizarem em suas aulas, pois sempre comentam, nas entrevistas, que usam textos, porém não especificam quais.

\section{QUADRO 3}

Relatos de Cleia e Goreth

\begin{tabular}{|l|l|}
\hline Cleia & \multicolumn{1}{|c|}{ Goreth } \\
\hline $\begin{array}{l}\text { Eu trabalho português, mas para eles, por } \\
\text { exemplo, um texto desses do jornal e } \\
\text { compreenderem, mesmo buscando o que eles }\end{array}$ & $\begin{array}{l}\text { Primeiramente, por exemplo, se você } \\
\text { trabalhou um texto, do texto você faz a } \\
\text { já conplicação do vocabulário, você trabalha as } \\
\text { dificílimo }[. . .] \text { mas vamos supor que, a partir } \\
\text { desse texto: eu preparei as gravuras, preparei o } \\
\text { conhecimento, por exemplo, a significação de } \\
\text { palavras-chave. [...] peguei um texto de... }\end{array}$ \\
\hline
\end{tabular}

Durante toda a pesquisa, somente as professoras Teresa e Goreth especificaram o gênero discursivo utilizado em determinado evento.

\section{QUADRO 4}

Relatos de Teresa e Goreth

\begin{tabular}{|r|l|}
\hline \multicolumn{1}{|c|}{ Teresa } & Goreth \\
\hline $\begin{array}{r}\text { [...] olha, quase sempre a minha aula é } \\
\text { expositiva, então tem o resumo que eu passo } \\
\text { pra ele, faço a interpretação em Libras, então }\end{array}$ & $\begin{array}{l}\text { [...] digamos assim, um texto... uma crônica, } \\
\text { por exemplo. } \\
\text { escrevo no quadro primeiro, depois a gente faz } \\
\text { um questionário, faz ou um exercício de } \\
\text { qualquer tipo, né. E quando tem aula prática, } \\
\text { eu avalio a aula com um relatório ou eu levo } \\
\text { o relatório semipronto e eles preenchem ou eu } \\
\text { faço o relatório aqui no laboratório com eles. }\end{array}$ \\
\hline
\end{tabular}

Entretanto, acreditamos que professores e professoras ainda participam de forma incipiente de práticas externas ao contexto escolar e/ou específicas do mundo real, o que dificulta a identificação com os gêneros discursivos. Logo, 
um maior conhecimento desse assunto por parte dos/as participantes facilitaria suas práticas em sala de aula. Com o uso adequado de textos, poderiam selecionar de maneira objetiva quais gêneros poderiam ser explorados com as alunas e os alunos surdos, bem como a forma de utilizá-los em sala de aula, com uma metodologia diferenciada.

Uma característica da mudança social, segundo Fairclough (2001), é o surgimento de novos gêneros. A cada nova articulação da prática social, como os contextos (escolas pesquisadas) situados no tempo e no espaço, que passaram de escolas regulares para escolas regulares inclusivas, vimos surgirem novos gêneros discursivos ou a adaptação de um gênero de uma prática fronteiriça para o novo uso social.

Com o cruzamento do discurso de Ensino Regular (que prioriza os conteúdos) com o discurso do Ensino Especial (que prioriza a adequação), surgem os gêneros híbridos, como nos exemplos vistos no QUADRO 2. Os gêneros emergem a partir de gêneros preexistentes. Essas mudanças acontecem no âmbito da linguagem, da estrutura composicional, da seleção vocabular e dos propósitos, transformando os gêneros já conhecidos em gêneros das práticas de letramento inclusivo. Nesse processo, a identificação com as práticas fronteiriças faz com que as pessoas envolvidas explorem os gêneros com os quais se identificam, na tentativa de fazer a sua transposição para os novos usos.

Nas práticas de letramento inclusivo, a identidade docente no Ensino Regular é tradicional, no sentido de que professores e professoras percebemse como responsáveis integrais pela aquisição dos conhecimentos escolares. Se a aprendizagem não ocorre, eles ou elas não conquistaram qualidades pessoais sensitivas (ver, olhar). A metáfora de cego/cegueira (MAGALHÃES, 1995) é atribuída, normalmente, pelas pessoas que estão na condição de iletradas à sua autoidentidade. É assim que professores e professoras, altamente letrados no letramento escolar, consideram-se cegos, incapazes, ante uma prática de letramento que ainda não lhes foi permitida: são cegos e surdos, porque não sabem como agir, incluir, desenvolver os gêneros discursivos adequados à prática de letramento inclusivo.

\section{A inclusão de alunos e alunas com Síndrome de Down}

a) O contexto de Brasília

Dentro do processo de inclusão vivenciado por Brasília, as itinerantes eram profissionais altamente capacitadas, com larga experiência no Ensino 
Especial em escolas exclusivamente especiais. Com o movimento conhecido

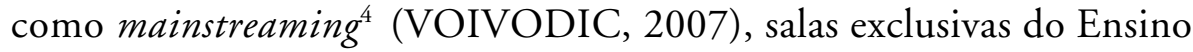
Especial foram esvaziadas e as profissionais foram deslocadas para o atendimento a docentes do Ensino Regular que passariam a atender alunos e alunas da inclusão.

Nesse novo contexto, surge o profissional itinerante, 5 como a professora Sílvia, designada para auxiliar professores e professoras desde o início do processo de inclusão (mainstreaming), em 2004, e por isso seu relato é considerado peça-chave, já que seu papel era integrar a prática políticoeducacional da Secretaria de Educação e a prática docente no ambiente investigado.

\section{QUADRO 5}

Relato da professora itinerante

\begin{tabular}{|l|}
\hline \multicolumn{1}{|c|}{ Sílvia } \\
\hline [...] Eu estou no Ensino Especial há dez anos, sou especialista em Educação Inclusiva, minha \\
pós-graduação foi na área, a minha monografia foi sobre deficiência mental e perspectivas \\
neurocientistas [...] então hoje eu tenho 12 [alunos/as] do Bia 1 - Bloco Inicial de \\
Alfabetização, o Bia 1, do bloco do Bia 1 até o Ensino Médio, então tem aluno de todos os \\
níveis, tem alunos concluindo o Ensino Médio esse ano, tem de tudo, é muito bacana. [...] \\
Então existe o curso de capacitação, a gente vê esse curso, quando a gente diz capacitação, \\
com uma reserva porque a gente não acredita que em seis encontros a gente possa capacitar \\
ninguém. [...] esse curso é também uma parceria com a Secretaria da Educação promovido \\
pelo MEC: Educação Inclusiva, direito à diversidade. [...] Somos nós da itinerância que \\
proporcionamos esse curso. [...] E é muito legal você estar visitando essas famílias, esses alunos \\
a história deles pra chegarem aqui.
\end{tabular}

Sívia teve seu papel construído em um cenário de intensas transformações. A prática de letramento inclusivo proposta pelo Plano Nacional de Educação (PNE) previa a inserção da pessoa com deficiência no contexto do Ensino Regular, e esse processo nas escolas do Distrito Federal (bem como nos outros

\footnotetext{
${ }^{4}$ No Brasil, convencionou-se o uso do termo "integração" como equivalente a mainstreaming, termo referente aos programas nascidos na década de 1970 nos Estados Unidos, que propunham uma série de açôes educacionais para deficientes, com objetivo de incluí-los no Ensino Regular, com apoio de atendimentos complementares.

${ }^{5}$ A partir de 2008, com a implantação das salas de recursos (hoje denominadas de Atendimento Educacional Especializado-AEE), as professoras itinerantes retornaram as atividades de regência.
} 
Estados pesquisados) foi percorrido, em grande parte, sob a influência dessas educadoras. Nesse primeiro recorte da fala de Sílvia, temos uma demonstração da figura da itinerante. Quando ela diz que "está" no Ensino Especial, sugere que sua identificação é como educadora, portanto está apta tanto para o Ensino Especial como para o Ensino Regular Inclusivo. Há, igualmente, uma relação identificacional mais estreita com o papel de itinerante, indicada pelo uso de "Nós, da itinerância", que confere status à função, reconhecida pelo Ministério. O status oferece a Sílvia uma condição híbrida: ao mesmo tempo que é professora, ela pertence ao quadro administrativo da Secretaria de Educação e é formadora do MEC.

Seu letramento institucional não ofusca sua percepção quanto ao discurso veiculado nos próprios cursos que oferece. Pela experiência no letramento do Ensino Especial, mantém-se crítica quanto aos treinamentos. A oferta dos cursos pela itinerância é avaliada como algo positivo à sua posição de itinerante, porém sua visão de especialista no Ensino Especial lhe diz que isso não é suficiente. Suas identidades são conflitantes, indicando uma estrutura ainda em construção, que é o ensino inclusivo.

Segundo Sílvia, houve então fortes resistências do corpo docente da escola, que culminaram na desistência de uma aluna com Síndrome de Down, em 2005. A permanência de uma pessoa com a Síndrome de Down na sala de aula tanto envolve uma mudança na perspectiva do que "deve" ser trabalhado, em termos de conteúdo e estratégia, como põe em pauta os valores e resultados a serem buscados por esses professores e professoras. ${ }^{6}$

No processo de implantação das práticas de letramento inclusivo, houve um preparo burocrático, com treinamentos rápidos (seis encontros) para alguns professores e professoras. Igualmente, a presença de uma itinerante daria o suporte técnico, pedagógico e ideológico para o trabalho da inclusão. Esse aparato foi proposto pela política da Secretaria de Estado da Educação, em cumprimento às metas do plano de erradicação do analfabetismo. Além do aparato na escola, houve uma reorganização administrativa para que na Secretaria de Educação houvesse igualmente o ordenamento público (normas, recursos orçamentários, recursos humanos, documentaçōes, etc.).

\footnotetext{
${ }^{6}$ A escola não se mostra um local neutro (BOURDIEU, 2005, p. 84). A diferença, segundo Silva (2000), está na forma como as identidades são imaginadas, no caso, as identidades docente e discente.
} 
O poder de Sílvia sobre os demais professores e professoras era manifestado por meio da hierarquia na posição - representava a Secretaria de Educação e o controle do conhecimento no Ensino Especial, que os outros não possuíam. As interaçôes entre Sílvia e colegas que compunham as estratégias de "sensibilização" permitiam o acesso ao discurso da Educação Especial e ao discurso institucional.

QUADRO 6

Relato de Sílvia

\begin{tabular}{|l|}
\hline \multicolumn{1}{|c|}{ Sílvia } \\
\hline [...] e aí a gente, normalmente, a gente tenta pelo bom senso, né, por uma pedagogia do amor, \\
se não a gente vai pela legislação, quando você mostra pra ele a legislação, que ele não está \\
fazendo favor em aceitar esse aluno na escola, é um direito do aluno estar aqui, hoje nem \\
mesmo a matrícula desse aluno pode ser negada, a lei garante a matrícula dele, e aí quando \\
você mostra a adequação curricular, como ela deve ser feita, documentada na forma da lei, aí \\
eles fazem, não fazem sorrindo, fazem por fazer [...].
\end{tabular}

A pedagogia do amor, termo utilizado pela itinerante, compreende a tentativa de convencimento pelos argumentos ideológicos relacionados à Educação Especial e aos valores humanos. Sílvia pretendia que a ideologia fosse aceita, mas a prática educacional que ela oferecia aos professores e professoras não correspondia aos usos do letramento a que eles ou elas tiveram acesso. $\mathrm{A}$ falta de acesso ao letramento da Educação Especial foi um obstáculo vencido pela força, pelo poder dominante institucional: "se não a gente vai pela legislação". Porém, o discurso legal teria força por si mesmo se ela não estivesse imbuída da vontade de que eles ou elas percebessem os alunos e as alunas da inclusão como capazes e merecedores de crédito, como em sua fala inicial: "Porque aqui é o lugar dele, se não chegar hoje, como é que vai ser daqui a um tempo?". Outros discursos são então mobilizados, como o discurso da "educação para todos", materializado em "é um direito do aluno estar aqui".

Para aproximar da vivência de professores e professoras o discurso do direito, Sílvia traz para a interação uma prova de que esse direito está consolidado e que o processo de inclusão não foi apenas iniciado. Essa prova está ao afirmar que "a lei garante a matrícula dele", bem como na forma em que a lei define o procedimento - "a adequação curricular como ela deve ser feita, documentada na forma da lei" -, o que torna seu argumento legítimo.

Ao dizer que "ele não está fazendo favor em aceitar esse aluno na escola", há um pressuposto de que professores e professoras em algum momento 
teriam tido o poder, teriam sido detentores da escolha. Esse poder foi então questionado e transferido para outras instâncias, como a política e a jurídica, que passam a definir o modus operandi da escola. Daí não estarem fazendo favor, mas cumprindo estritamente o que lhes foi determinado, ou seja, a inclusão na forma da lei.

Os discursos atuam sobre as práticas, modificando-as, envolvendo seus atores e constituindo novas identidades (FAIRCLOUGH, 2003). No processo de inclusão no letramento inclusivo burocrático-administrativo, com o fim claro de convencimento, Sílvia adota estratégias de diálogo mais pelo lado flexível, para ganhar a simpatia do grupo, que pela assimilação da proposta atua sobre os demais. Por meio do letramento inclusivo burocráticoadministrativo, o letramento inclusivo pedagógico ${ }^{7}$ foi sendo construído no interior dos discursos e das práticas.

\section{b) O contexto de Goiânia}

Em Goiás, diferentemente de Brasília, a inclusão da pessoa com Síndrome de Down ainda está iniciando. Nos anos 2010 e 2011, não verificamos muitos municípios com alunos ou alunas com Síndrome de Down incluídos nas séries finais do Ensino Fundamental ( $6^{\circ}$ ao $9^{\circ}$ ano). Essa realidade faz parte da política estadual, que ainda manteve de alguma forma os atendimentos nas associações e organizaçõos como a Associação de Pais e Amigos de Excepcionais (Apae) e a Associação Down (ASDOWN).

O modelo da inclusão em Goiás é semelhante: as escolas possuem salas regulares, em que alunos e alunas com Síndrome de Down são atendidos concomitantemente com alunos regulares. Nesse espaço, ocorre a atuação da professora de apoio. ${ }^{8}$ Essas professoras mantinham-se presentes em sala durante todas as aulas, ficando uma por sala. Elas auxiliavam alunos e alunas nos registros do conteúdo e/ou da atividade, para posteriormente auxiliá-los no conteúdo. São as professoras de apoio que realizam a adaptação curricular, assim como aplicam o contraturno, momento em que alunos e alunas da

\footnotetext{
${ }^{7}$ Adotamos o termo "práticas de letramento inclusivo" como uma prática mais ampla, na qual os letramentos podem ser utilizados para o fim da inclusão. O letramento burocrático-administrativo é considerado como oriundo dos órgãos administrativos e políticos, e os letramentos pedagógicos aqueles propostos por professores e professoras no contexto da escola.

${ }^{8}$ Todas eram do sexo feminino.
} 
inclusão recebem atendimento personalizado. Em uma das escolas, alunos e alunas possuem deficiência intelectual, sendo necessário o acompanhamento e a adequação. Em outra, não havia essa necessidade, porque o/a estudante não tinha perda cognitiva. Possuía baixa visão, mas não apresentava deficiência intelectual que justificasse mudança na grade de conteúdos. Contudo, a professora de apoio permanecia a seu lado em todos os horários de aula.

Sob o ponto de vista protetivo, vimos em Goiás uma preocupação maior no acompanhamento desses alunos e alunas. Uma escola possuía três professoras de apoio que, além de assistirem às aulas com alunos e alunas, responsabilizavam-se pela parte pedagógica e pelas atividades comuns. Nas palavras de Elisa, ela avalia a educação inclusiva da seguinte forma:

QUADRO 7

Relato de Elisa

\begin{tabular}{|l|}
\hline \multicolumn{1}{|c|}{ Elisa } \\
\hline Olha, no Ensino Regular, o que eu pude observar, que as nossas crianças que saíram da Apae \\
e foram pro Ensino Regular, eles estavam inclusos na escola, mas como os alunos não. É uma \\
porcentagem mínima de vinte a trinta por cento só que ficaram inclusos socialmente, porque \\
os outros continuaram assim, isolados, né? Todos eles desistiram e voltaram pra Apae. Não \\
houve rendimento.
\end{tabular}

A professora Elisa faz uma dura observação: "eles estavam inclusos na escola, mas como os alunos não”. A educação inclusiva trouxe alunos e alunas com Síndrome de Down para o ambiente escolar. Porém, nesse novo contexto, essas pessoas não eram vistas como parte do grupo discente. A maior parte voltou para a Apae, porque "Não houve rendimento", isto é, não houve avanços pedagógicos para alunos e alunas incluídos. Essa constatação também foi consensual entre docentes quando explicaram que não conseguem dar atenção aos alunos especiais porque outros trinta aguardam atenção. Ficam em crise por não conseguirem cumprir com seus objetivos. Sobre as dificuldades em trabalhar no Ensino Regular Inclusivo, Elisa ainda explica: 


\section{QUADRO 8}

Continuação do relato da professora Elisa

\begin{tabular}{|l|}
\hline \multicolumn{1}{|c|}{ Elisa } \\
\hline Olha, pelo que eu vi, os professores do Ensino Regular estão reclamando muito, achando \\
muito difícil, porque eles não estão bem preparados. Eles assim, sempre quando eu converso \\
com eles, eles dizem assim, que pelo menos, a direção que vem lá de cima, deveria pelo menos \\
preparar o professor primeiro. Então eles não estavam preparados, como ainda não estão \\
devidamente preparados. Falta intérprete, falta material de recursos didáticos pra poder \\
ajudar os alunos. Eles reclamaram foi isso.
\end{tabular}

Na percepção de Elisa, vemos a política pública, “a direção que vem lá de cima”, como a principal responsável pelos procedimentos adotados. A professora tem a clara noção de que "eles" deveriam preparar tanto o ambiente, dotando a escola de recursos materiais, como os recursos humanos, preparando profissionais. A identidade da professora assume, nesse trecho, o papel de professora do Ensino Especial, ao mencionar "os professores do Ensino Regular estão reclamando muito”. Para ela, a dificuldade vem da necessidade de conhecimento técnico para o trabalho com estudantes especiais. Essa visão destoa do senso comum de que as mulheres estejam preparadas para o exercício da Educação Especial por serem maternais. Elisa deixa claro que isso é um dever técnico. A professora percebe a necessidade de formação e de preparo para o desempenho do papel docente. Reconhece que não há esse preparo e vê na educação regular inclusiva a fonte para o descontentamento de docentes. Por fim, ela discorre sobre a principal diferença entre o Ensino Regular e o Especial, destacando os requisitos para trabalhar na educação inclusiva:

\section{QUADRO 9}

Continuação do relato de Elisa

\begin{tabular}{|l|}
\hline Elisa \\
\hline [o professor deve ter] Paciência, tolerância, ACREDITAR no aluno, ele tem que \\
ACREDITAR no aluno e ACREDITAR que ele é capaz, porque se ele não tem condição ele \\
tem que ir em busca, pra oferecer pro aluno o que o aluno verdadeiramente necessita! \\
(chorando) Eu até me emociono! O professor não preocupa! Sabe? Ele precisa de investir, ele \\
tem que acreditar! Ele tem que dar carinho, tem que dar apoio, ele TEM que gratificar a \\
criança! Por pequeno que seja o salto que ele deu, o professor tem que gratificar aquele aluno \\
por aquilo ali!
\end{tabular}


Elisa chora ao falar da realidade: a falta de adesão, de investimento emocional, de sensibilidade para com as necessidades de estudantes especiais. Essa nova escola difere muito da proposta das Apaes, e isso traz a noção de abandono desses alunos e alunas especiais. Por outro lado, ela reconhece que faltam recursos e treinamentos, mas aquilo de que a professora mais se ressente é a precariedade do atendimento feito nas escolas regulares, promovido tanto pelo governo como pelo corpo docente. Concluímos, assim, que a construção de uma realidade mais positiva nas escolas públicas passa pela transformação da identidade docente e pela elaboração de políticas públicas eficientes. Letramentos voltados para a educação inclusiva, treinamentos e capacitação, além de estrutura e recursos pedagógicos, teriam de fazer parte do cotidiano da escola regular inclusiva, o que, infelizmente, não foi a realidade observada nas escolas pesquisadas nos quatro Estados.

\section{O Atendimento Educacional Especializado}

O Atendimento Educacional Especializado (AEE) é um serviço da educação especial que "[...] identifica, elabora e organiza recursos pedagógicos e de acessibilidade, que eliminem as barreiras para a plena participação dos alunos, considerando suas necessidades específicas" (BRASIL, 2011). Além disso, complementa e/ou suplementa a formação de alunos e alunas, visando à sua autonomia na escola e fora dela, constituindo, assim, oferta obrigatória pelos sistemas de ensino. É realizado, de preferência, nas escolas regulares, em um espaço físico denominado Sala de Recursos Multifuncionais. Portanto, deve ser parte integrante do projeto político-pedagógico da escola.

O Atendimento Educacional Especializado em Teresina e em Fortaleza possui profissionais em comum, porém diferentes em relação a Brasília, conforme será descrito no QUADRO 10, a seguir. 


\section{QUADRO 10}

O Atendimento Educacional Especializado em Brasília, Fortaleza e Teresina

\begin{tabular}{|c|c|c|}
\hline Cidades & Serviços & Profissionais \\
\hline Brasília (DF) & $\begin{array}{l}\text { Classes comuns do Ensino Regular; } \\
\text { Classes especiais; Classe de educação bilíngue } \\
\text { Sala de recursos - AEE } \\
\text { Centro de Ensino Especial de Deficientes Visuais } \\
\text { Centro de Apoio Pedagógico (CAP) } \\
\text { às Pessoas com Deficiência Visual }\end{array}$ & $\begin{array}{l}\text { Professores/as do } \\
\text { Ensino Regular } \\
\text { Professores/as especialistas } \\
\text { em AEE } \\
\text { Pedagoga } \\
\text { Psicóloga } \\
\text { Orientadora Educacional }\end{array}$ \\
\hline Fortaleza (CE) & $\begin{array}{l}\text { Classe comum (inclusão); Classe especial } \\
\text { Sala de recursos multifuncionais } \\
\text { Sala de Apoio pedagógico específico } \\
\text { Escola especial e/ou instituiçóes especializadas } \\
\text { Núcleo de atendimento pedagógico } \\
\text { especializado }\left(\mathrm{NAPE}^{9}\right)\end{array}$ & $\begin{array}{l}\text { Professores/as } \\
\text { Pedagogos/as } \\
\text { Psicólogos/as } \\
\text { Terapeutas Ocupacionais } \\
\text { Assistentes Sociais }\end{array}$ \\
\hline Teresina (PI) & $\begin{array}{l}\text { Sala de recursos multifuncionais } \\
\text { AEE }\end{array}$ & $\begin{array}{l}\text { Professores/as } \\
\text { Pedagogos/as } \\
\text { Psicólogos/as } \\
\text { Terapeutas Ocupacionais } \\
\text { Assistentes Sociais }\end{array}$ \\
\hline
\end{tabular}

Barton, Hamilton e Ivanic (2000, p. 1, tradução nossa) sugerem que, "ao observamos os eventos, é possível perceber que há diversos letramentos". Nas escolas pesquisadas, durante a observação, principalmente das salas de atendimento, constatamos que os/as participantes utilizam-se de diversos letramentos no decorrer das suas atividades e práticas, principalmente pelo letramento burocrático, conforme podemos observar no QUADRO 11, a seguir.

${ }^{9}$ Espaço equipado com recursos materiais e humanos específicos, implantado e organizado no âmbito das unidades escolares, que realiza atendimento essencialmente pedagógico, através de uma equipe multiprofissional composta de pedagogos e/ou psicopedagogos, assistentes sociais, psicólogos, fonoaudiólogos, terapeutas ocupacionais. Apresenta como principal finalidade dar suporte às escolas no processo inclusivo dos educandos com necessidades educacionais especiais, através da avaliação, encaminhamento a serviços especializados e acompanhamento pedagógico. 
QUADRO 11

Letramento burocrático

\begin{tabular}{|c|c|c|c|}
\hline \multicolumn{2}{|c|}{ Brasília } & \multicolumn{2}{|l|}{ Fortaleza } \\
\hline Gerência de EE: & Professor/a do AEE: & Professora do AEE: & NAPE: \\
\hline $\begin{array}{l}\text { - Formulário de Registro } \\
\text { do Plano Pedagógico } \\
\text { Individual } \\
\text { - Formulário de Registro } \\
\text { das Adequaçóes } \\
\text { - Formulário de Registro } \\
\text { do Plano de Atendimento } \\
\text { Complementar } \\
\text { - Plano de AEE }\end{array}$ & $\begin{array}{l}\text { - Ficha de identificação } \\
\text { do aluno ou aluna } \\
\text { - Termo de } \\
\text { responsabilidade } \\
\text { - Autorizaçáo de saída } \\
\text { - Autorização para } \\
\text { pesquisa } \\
\text { - Termo de desistência } \\
\text { - Diário de classe }\end{array}$ & $\begin{array}{l}\text { - Instrumental } \\
\text { pedagógico } \\
\text { - Instrumental de } \\
\text { acompanhamento de } \\
\text { alunos e alunas incluídos }\end{array}$ & $\begin{array}{l}\text { - Folha de } \\
\text { encaminhamento } \\
\text { - Anamnese } \\
\text { - Avaliação pedagógica, } \\
\text { psicológica, fonoaudio- } \\
\text { lógica e em terapia } \\
\text { ocupacional } \\
\text { - Parecer avaliativo } \\
\text { - Cartão } \\
\text { - Parecer evolutivo } \\
\text { - Parecer de reavaliação } \\
\text { pedagógica }\end{array}$ \\
\hline
\end{tabular}

A quantidade de formulários e fichas que a Educação Especial produz é muito superior à do Ensino Regular. Em Brasília, cada aluno ou aluna possui uma ficha de identificação, na qual constam os dados da criança ou jovem e as intervenções propostas. Contudo, sua utilização requer o desenvolvimento de folhas de acompanhamento que devem ser preenchidas mensalmente. Nesse acompanhamento, além de dados técnicos sobre a deficiência, para cujo preenchimento professores e professoras não possuem competência técnica, mas que precisam ser informados, devem ser registradas também as adequações e avaliaçōes individuais de cada aluno e aluna.

Em Brasília, contexto de maior volume de crianças incluídas, um único professor ou professora chega a ter mais de 40 alunos especiais. Esse letramento burocrático também se estende ao atendimento especializado. Compreendemos que o processo de inclusão iniciado nas políticas públicas deu-se mediante ação direta dos órgãos administrativos, como as secretarias, regionais e delegacias de ensino. Nesse ambiente, o letramento burocrático torna as rotinas muito mais explícitas. Segundo Barton e Hamilton, na obra de Barton, Hamilton e Ivanic (2000), letramentos cruzam fronteiras nas interseções das práticas.

No processo de inclusão, criou-se, com os mecanismos legais, um ponto de contato entre os órgãos administrativos e as escolas. Esse ponto permitiu que as práticas burocráticas, na ausência de maior identificação com o letramento da educação especial, povoassem o ambiente escolar, caracterizando a educação especial inclusiva mais como uma modalidade burocráticoadministrativa do que propriamente pedagógica. 


\section{Considerações finais}

Os discursos tradicionais sobre a educação foram perceptíveis tanto na fala de docentes e pedagogas como nas práticas de letramentos diários. Docentes viam-se como responsáveis pelo desenvolvimento sócio-cognitivo de aprendizes. Seus princípios em relação à docência pairavam sobre como deveriam manter-se como exemplos, e viam em seus papéis uma importância social que não é reconhecida pelos governos.

O reconhecimento a que se referem trata de estruturas de sala de aula, estrutura de apoio na educação especial/educação inclusiva, assim como recursos e menor número de discentes por sala de aula, e, quanto à inclusão, a necessidade de serem informados e de optarem quanto à modalidade de ensino a que teriam exercício, se inclusiva ou regular. Porém, os discursos mesclaramse, como o discurso do Ensino Especial, promovido tanto pela educadora itinerante como no contato com textos pedagógicos, o discurso religioso (respeito ao ser com base em princípios cristãos) e o discurso de gênero relacionado à representação das mulheres como mais apropriadas para o estabelecimento dos laços afetivos com alunos e alunas especiais. Por fim, vimos discursos críticos nas vozes de docentes e discursos hegemônicos (governamentais) que impõem e controlam a prática da inclusão.

Nas práticas de letramento, professores e professoras afirmam-se como profissionais, em um discurso contra-hegemônico, no sentido de perceberem a mudança que poderiam promover para a inserção real de alunos e alunas, ainda que com poucos recursos e com a consciência de que tais recursos devem ser supridos pela gestão pública.

As atividades em sala de aula privilegiaram os conceitos de ética, promoção da valorização da diferença, autoaceitação e respeito humano, nas práticas promovidas tanto pelos homens como pelas mulheres. No entanto, chamou-nos a atenção o fato de que as mulheres dedicaram maior tempo à elaboração de gêneros discursivos que proporcionassem o ensino desses temas, enquanto os homens privilegiaram a abordagem em termos interacionais, dedicando maior tempo à exploração de gêneros discursivos que abordassem conteúdos tradicionais, com vistas à inclusão. Essas práticas reproduzem conceitos de gênero, uma vez que se atribui, no senso comum, à mulher $\mathrm{o}$ papel de educar e ao homem o de instruir.

Vimos também que tanto mulheres como homens são, no contexto do Ensino Regular Inclusivo, dedicados professores que se preocupam com suas práticas e buscam minimizar os efeitos da falta de recursos de que a escola 
regular é objeto. Nesse sentido, a educadora itinerante tentou ser a intermediária entre uma escola e a Secretaria de Educação para obtenção de parte dos materiais pedagógicos, mas de forma insuficiente.

As identidades docentes são situadas nas práticas de letramento em reconstruçōes sempre constantes. Tais reconstruções passaram de professores do Ensino Regular (quando se dizem não preparados) para professores do Ensino Regular Inclusivo (quando se sentem felizes ante os resultados). Igualmente revisaram posições, relacionadas ao afeto na prática docente, percebendo que vínculos de confiança no Ensino Especial são necessários.

Além disso, percebemos, nesta pesquisa, que professores e professoras buscaram rearticulações das práticas docentes alternativas para a promoção da inclusão, tomando por ponto de partida seus conhecimentos de mundo, inclusive vivências que são atravessadas pelos aspectos de gênero. A busca se pautou pela crítica, boa vontade e perseverança, valores cultivados por docentes, como parte de suas identidades. No entanto, ante o contexto em alta transformação, tais profissionais procuram por essas identidades e nelas investem com grande participação de meninos e meninas especiais. Não sem, obviamente, compartilharem de angústias e incertezas.

Por fim, nas práticas de letramento no Atendimento Educacional Especializado, observamos que os letramentos informais e burocráticos são predominantes. E como esse processo recentemente ganhou força no Brasil, fica evidente a presença, também, dos seguintes discursos: o tradicional, o da inclusão, o da diferença de gênero (que não desenvolvemos aqui ${ }^{10}$ ). Apesar disso, percebemos uma reflexão por parte dos profissionais, ao perceberem a necessidade de não reforçar as limitações, mas trabalhar as potencialidades, resultando, assim, uma mudança da prática.

\section{Referências}

ANGROSINO, M. Etnografia e observação participante. Tradução de José Fonseca. Porto Alegre: Artmed, 2009.

BAKHTIN, M. Estética da criação verbal. 2. ed. Tradução de Maria Ermantina Galvão G. Pereira. São Paulo: Martins Fontes, 1997.

BARTON, D. Literacy: an introduction to the ecology of written language. $2^{\text {nd }}$ Ed. Oxford; Cambridge: Blackwell, 2007.

${ }^{10}$ Ver Magalhães (2008). 
BARTON, D.; HAMILTON, M. Local literacies. London, New York: Routledge, 1998.

BARTON, D.; HAMILTON, M.; IVANIC, R. (Org.). Situated literacies: reading and writing in context. London; New York: Routledge, 2000.

BATISTA JR, J. R. L. Os discursos docentes sobre inclusão de alunas e alunos surdos no Ensino Regular: identidades e letramentos. 2008. 151 p. Dissertação (Mestrado em Linguística) - Curso de Pós-Graduação em Linguística, Universidade de Brasília, Brasília, 2008.

BLOOME, D. et. al. Discourse analysis and the study of classroom language and literacy events: a microethnographic perspective. New Jersey: Lawrence Erlbaum Associates, 2005.

BLOMMAERT, J. Discourse: key topics in sociolinguistics. Cambridge: Cambridge University Press, 2005.

BOURDIEU, P. A dominação masculina. Rio de Janeiro: Bertrand Brasil, 2005. BRASIL. Decreto n. 7.611, de 17 de novembro de 2011. Dispõe sobre a educação especial, o atendimento educacional especializado e dá outras providências. Brasília, 2011.

CHOULIARAKI, L.; FAIRCLOUGH, N. Discourse in late modernity: rethinking critical discourse analysis. Edinburgh: Edinburgh University Press, 1999.

FAIRCLOUGH, N. Analysing discourse: textual analysis for social research. London; New York: Routledge, 2003.

FAIRCLOUGH, N. Critical discourse analysis. $2^{\text {nd }}$ Ed. London; New York: Longman, 2010.

FAIRCLOUGH, N. Discurso e mudança social. Coordenação da tradução, revisão e prefácio à edição brasileira de Izabel Magalhães. Brasília: Editora Universidade de Brasília, 2001.

FLICK, U. Desenho da pesquisa qualitativa. Porto Alegre: Artmed, 2009a.

FLICK, U. Qualidade na pesquisa qualitativa. Porto Alegre: Artmed, 2009b.

FOUCAULT, M. A arqueologia do saber. 3. ed. Tradução de Luiz Felipe Baeta Neves. Rio de Janeiro: Forense Universitária, 1987.

FOUCAULT, M. Power/Knowledge: selected interviews and other writings. New York: Pantheon Books, 1980.

GEE, J. P. Teenagers in new times: a New Literacy Studies perspective. Journal of Adolescent \& Adult Literacy, v. 43, n. 5, Feb. 2000.

GEE, J. P. The new literacy studies and the social turn. 1999. Disponível em: <www.schools.ash.org.au/litweb/page300.html>. Acesso em: 10 fev. 2006. 
HAMMERSLEY, M.; ATKINSON, P. Ethnography: principles in practice. London; New York: Routledge, 2007.

HEATH, S. B. Ways with words: language, life and work in communities and classrooms. Cambridge: Cambridge University Press, 1983.

HEATH, S. B.; STREET, B. V. Ethnography: approaches to language and literacy research. New York; London: Teachers College Press, 2008.

MAGALHÃES, I. Discursos e identidades de gênero na alfabetização de jovens e adultos e no Ensino Especial. Calidoscópio, v. 6, n. 2, p. 61-68, 2008.

MAGALHĀES, I. Discurso, ética e identidades de gênero. In: MAGALHÃES, I.; GRIGOLETTO, M.; CORACINI, M. J. (Org.). Práticas identitárias: língua e discurso. São Carlos: Claraluz, 2006. p. 71-96.

MAGALHÃES, I. Teoria crítica do discurso e texto. Linguagem em (Dis)curso, v. 4, p. 113-131, 2004. Número especial.

MAGALHÂES, I. Práticas discursivas de letramento: a construção da identidade em relatos de mulheres. In: KLEIMAN, Angela (Org.). Os significados do letramento: uma nova perspectiva sobre a prática social da escrita. Campinas: Mercado de Letras, 1995. p. 201-235.

MAGALHÃES, I. Textos e práticas socioculturais - discursos, letramentos e identidades. Revista Linha D'Água, n. 24, v. 2, p. 217-233, 2011.

PRINSLOO, M.; BREIER, M. (Org.). The social uses of literacy. Bertsham, África do Sul; Amsterdã: John Benjamins, 1996.

RESENDE, V. Análise de discurso crítica e realismo crítico. Campinas: Pontes, 2009.

RIOS, G. Literacy discourses: a sociocultural critique in Brazilian communities. Saarbrucken: Verlag, 2009.

SATO, D. T. B. A inclusão da pessoa com Sindrome de Down: identidades docentes, discursos e letramentos. 2008. 149 p. Dissertação (Mestrado em Linguística) - Curso de Pós-Graduação em Linguística, Universidade de Brasília, Brasília, 2008.

SILVA, T. T. A produção social da identidade e da diferença. In: SILVA, T. T.

(Org.). Identidade e diferença: a perspectiva dos estudos culturais. Petrópolis: Vozes, 2000. p. 73-102.

STREET, B. (Org.). Literacy and development: ethnographic perspectives. London; New York: Routledge, 2001.

STREET, B. Literacy in theory and practice. Cambridge: Cambridge University Press, 1984. 
STREET, B. New literacies and the implications for education. Linguistics and Education, v. 10, n. 1, p. 1-24, 1998.

STREET, B. Social literacies: critical approaches to literacy in development, ethnography and education. London; New York: Longman, 1995.

TETT, L.; HAMILTON, M.; HILLIER, Y. (Org.). Adult literacy, numeracy and language. Maidenhead; New York: Open University Press, 2006.

VAN DIJK, T. El analisis crítico del discurso. Anthropos, Barcelona, n. 186, p. 23-36, 1999.

VOIVODIC, M. A. M. A. Inclusão escolar de crianças com Síndrome de Down. Petrópolis: Vozes, 2007.

Recebido em 15/03/2012. Aprovado em 02/06/2012. 